\title{
Treatment of dento-alveolar trauma: knowledge evaluation from southern Brazilian dentists
}

\author{
Renato Azevedo de Azevedo ${ }^{1}$, Marcos Britto Corrêa ${ }^{1}$, Marcos Antonio Torriani², Flávio Fernando Demarco', Rafael Guerra Lund \\ ${ }^{1}$ DDS, MS, PhD, Post-Graduate Program in Dentistry, Pelotas Dental School, Universidade Federal de Pelotas, Pelotas, RS, Brazil
}

${ }^{2} \mathrm{DDS}, \mathrm{MS}, \mathrm{PhD}$, Department of Surgery and Bucco-Maxilo-Facial Traumatology, Pelotas Dental School, Universidade Federal de Pelotas, Pelotas, RS, Brazil

Received for publication: January 23, 2017 Accepted: July 23, 2017

Correspondence to: Rafael Guerra Lund Faculdade de Odontologia da Universidade Federal de Pelotas

Rua Gonçalves Chaves, 457, Sala 503 - Centro CEP: 96015568 Pelotas, Rio Grande do Sul, Brazil

Phone: +55 5391257668

Fax: +555332226690

E-mail: rafael.lund@gmail.com

\begin{abstract}
Aim: This study aimed to evaluate through a specific survey the knowledge of dentists on dental trauma in Southern Brazil regarding their conduct facing some dental trauma injuries. Methods: A survey with five personal and five specific questions on knowledge about dental trauma was carried out with all dentists regularly registered in Pelotas, Brazil $(n=276)$. The data was submitted to descriptive statistical analysis and associations were tested by Chi-square test $(p \geq 0.05)$. Results: There were a higher number of dentists with up to 10 years since graduation ( $45.4 \%$ ) who worked in private dental office $(66.1 \%)$ and with some specialization $(63.7 \%)$. Dentists with more years since graduation were associated to less knowledge on dental trauma management $(p<0.001)$. Conclusions: The knowledge of the dentists related to dento-alveolar trauma is lowered with higher time in clinical practice. Continuing education courses should be offered to the dentists by educational institutions.
\end{abstract}

Keywords: tooth injuries, knowledge, cross sectional survey, dentists.

\section{Introduction}

It is estimated that in the near future the prevalence of dental alveolar injuries will exceed caries and periodontal diseases, and as a consequence it is considered a major public health problem among children and adolescents ${ }^{1,2}$. This is justified not only because of its relatively high prevalence reported in population studies, but also because it affects aesthetics, psychological and physical conditions of the individual, leading to a reduction in quality of life ${ }^{3,4}$. Furthermore, treatment of dento-alveolar trauma frequently requires complex treatment and long term follow-ups, causing significant economic consequences ${ }^{5}$.

Due to the importance of injuries caused by dental trauma, the International Association of Dental Traumatology (IADT), which is a professional organization responsible for promoting optimal prevention and treatment services regarding dental trauma lesions through interaction with doctors and dentists, makes available in its website three guidelines: the first dealing with the management of injuries with fracture dislocations of permanent teeth with closed or opened apex; the second dealing 
with management of injuries such as avulsion of permanent teeth with open or closed apex; and the third dealing with management of dental injuries in deciduous teeth ${ }^{6}$. In all guidelines it can be easily found the immediate and most adequate treatment for each case, as well as the immediate recommendations for post-treatment and follow up of each case. These guidelines were designed by a group of experts who came to a consensus after a literature review and group discussions on each subject ${ }^{7}$.

Facing a dento-alveolar trauma, a diagnosis based on an adequate clinical examination with a written, radiographic and in many cases photographic record, can eliminate many doubts, which the dentist may have, leading to a correct choice of treatment. Considering that in patients who suffered dental trauma many of the late complications are consequence of failure in the first assessment ${ }^{8}$, it is of great importance that the dentist has the necessary knowledge to identify the various types of dental trauma and their possible treatments. In this case, the correct choice of emergency procedure will result in a more favorable prognosis for the affected tooth ${ }^{9}$.

The organization of services and primary care teams for oral health present, in general, a low level of knowledge on management of dento-alveolar trauma ${ }^{10,11}$. Even though there are available guidelines for dental professionals, some studies in different countries have also demonstrated that the knowledge of dental professionals on dento-alveolar trauma is insufficient ${ }^{11-13}$. In Brazil some studies were carried out on the subject ${ }^{9,14-16}$, with results similar to those observed in other countries, showing lack of dentist's knowledge on management of dental trauma emergency. Besides the low level of knowledge, it was verified that dentists with a longer time since graduation had an even worse performance ${ }^{14}$, highlighting the need for constant updates in this area of expertise.

Thus, it is clear that the knowledge of dental professionals should be evaluated regarding their conduct facing dental trauma emergency injuries, aiming at identifying the main weaknesses related to this issue and allowing the development of strategies in order to improve this knowledge. This study aims to assess the knowledge of dentists from the city of Pelotas, Brazil, regarding their conduct towards dento-alveolar trauma and to test its association to the time since graduation, expertise area and gender.

\section{Material and Methods}

This cross-sectional study was carried out in Pelotas, a city in an affluent area of south of Brazil. This city is the third most populated in Rio Grande do Sul state (327,778 inhabitants) with an area of $1,609 \mathrm{~km}^{2}$, and $95 \%$ of its population lives in urban areas.

According to $\mathrm{CRO}$ - Conselho Regional de Odontologia (Regional Council of Dentistry), $4.3 \%$ of all dentists from Rio Grande do Sul state are working in Pelotas. All dentists from Pelotas regularly registered in the Regional Council and with updated address information were contacted and asked to respond the questionnaire.
The total number of registered dentists (target population of dentists from Pelotas) was 276 professionals. Dentists who did not work anymore (retired or working in other area) were excluded of the study.

This study was submitted to the Ethics Committee in Research of a Faculty of Dentistry of an University, with approval number 116/2009. Previously to the interview, the participants signed a Consensual Agreement. The identity of the professionals who accepted to take part in the survey was protected.

A questionnaire was developed containing structured questions concerning dentist professional background and five specific questions about their knowledge about the procedures to be adopted facing several kinds of dento-alveolar trauma, such as fractures with pulp involvement, root fractures and avulsions. These questions were taken from a questionnaire described in a study by $\mathrm{Hu}$ et al. ${ }^{9}$

Undergraduate dental students visited the dentists participants in the second semester of 2010. The questionnaires were handed in person and the importance and aim of the study was explained. Approximately one week after the delivery of the questionnaires, they were collected together with the consensual agreement form signed. This way, the dentists were not interrupted in their workplace at working hours and did not feel uncomfortable with the interviewers.

The answers to the questions related to dento-alveolar trauma were analyzed independently and grouped. For analysis of associations, the number of questions answered correctly was quantified and further dichotomized in: 0 to 2 correct answers or 3 or more correct answers.

The independent variables were gender, skin color, time since graduation, workplace, level and area of specialization. The variable skin color was self-referred by the professional according to the classification of Brazilian Institute of Geography and Statistics (IBGE) in white, black, brown, yellow and indian. Time since graduation was recorded in a continuous way and was categorized in up to 10 years, 11 to 20 years, 21 to 30 years and more than 30 years since graduation. The workplace was recorded by asking in which place the dentist worked most of the time, and categorized as public work, private dental office, and teaching (University). The degree of specialization was recorded by asking if the dentist had any kind of post-graduation. It was categorized in yes or no.

Data obtained from the questionnaires were processed in Excel spreadsheet and submitted to descriptive analysis to obtain the relative and absolute frequencies of the answers with their respective $95 \%$ confidence intervals. The answers considered correct were based on IADT guidelines. The analysis of associations between independent variables and knowledge on dento-alveolar trauma was performed by chi-square test. The software used for statistical analysis was Stata ${ }^{11}$.

\section{Results}

Out of 276 dentists (target population), 187 (sample obtained, 68\%) answered the questionnaire. Table 1 shows the 
description of the sample that took part in the study according to the variables surveyed. It can be observed that the distribution of dentists regarding gender was proportional between men and women, while $96.8 \%$ of them were of white color. In relation

Table 1 - Descriptive analyses of the relative variables related to dentists in Pelotas, Brazil $(\mathrm{n}=187)$.

\begin{tabular}{lcc}
\hline $\begin{array}{l}\text { Variables/Categories } \\
\text { Gender }\end{array}$ & Absolute frequency $(\mathrm{n})$ & $\begin{array}{c}\text { Relative frequency } \\
{[\%(\mathrm{Cl}, 95 \%)]}\end{array}$ \\
Male & 89 & $47.6(40.3-55.0)$ \\
Female & 98 & $52.4(45.0-59.7)$ \\
Color & & \\
White & 180 & $96.8(93.1-98.8)$ \\
Black & 2 & $1.1(0.1-3.8)$ \\
Brown & 4 & $2.2(0.1-5.3)$ \\
Years since graduation & & \\
Up to 10 & 84 & $45.4(38.2-58.9)$ \\
11 to 20 & 43 & $23.2(17.2-29.7)$ \\
21 to 30 & 28 & $15.1(10.2-20.9)$ \\
More than 30 & 30 & $16.2(11.1-22.1)$ \\
Workplace & & \\
Private & 121 & $66.1(59.1-73.0)$ \\
Public & 39 & $21.3(15.7-28.0)$ \\
Teaching & 23 & $12.6(8.4-18.5)$ \\
Specialization & & \\
Without post-graduation & 66 & $36.3(29.5-43.7)$ \\
With post-graduation & 116 & $63.7(56.3-70.5)$ \\
\hline
\end{tabular}

to the variables relating to profession, there were a higher number of dentists with up to 10 years since graduation $(45.4 \%)$ who worked in private dental office $(66.1 \%)$ and with some specialization $(63.7 \%)$.

In Table 2, relative and absolute frequency values are shown for each alternative to the questions answered by the dentists. The correct alternatives to each question in the table are in bold and italics. It is possible to observe that the majority of the dentists interviewed answered correctly the questions. In question number 3 (Table 2) that addresses a case of root fracture, the majority of dentists interviewed (38.8\%) indicated the treatment with rigid splint, which contradicts the IADT guidelines. This was the only question with a relative frequency of correct answer lower than $50 \%$.

Table 3 shows the number of right answers, where it can be observed that, from 187 dentists interviewed, 13 (7\%) did not answer any question correctly and 14 (7.5\%) answered five questions correctly. The majority of the interviewed dentists answered two $(24.6 \%)$ and three $(28.9 \%)$ questions correctly.

In the association analysis between the number of correct answers and the independent variables studied (Table 4), only the variable related to years since graduation was associated to the outcome $(\mathrm{p}<0.001)$, and a downward trend in the number of correct answers was observed as the years after graduation increased.

Table 2 - Absolute (n) and relative (\%) frequencies of dentist's answers to questions about dental trauma. Pelotas, Brazil. (n=187).

\begin{tabular}{|c|c|}
\hline Question & $\mathrm{n}[\%(\mathrm{Cl}, 95 \%)]$ \\
\hline $\begin{array}{l}\text { 1. What kind of splint and for how long should it be used for? } \\
\text { (0) rigid, during } 2 \text { weeks or until the mobility of the tooth is reduced } \\
\text { (1) semi-rigid or rigid, for } 1 \text { month } \\
\text { *(2) semi-rigid, during } 2 \text { weeks or until the mobility of the tooth is reduced }\end{array}$ & $\begin{array}{l}40[24.4(18.6-31.4)] \\
26[15.9(11.1-22.1)]\end{array}$ \\
\hline (3) no splint should be used & $\begin{array}{l}93[56.7(49.363 .9)] \\
\quad 5[3.0(1.2-6.8)]\end{array}$ \\
\hline \multicolumn{2}{|l|}{ 2. In this case, would you prescribe any medicine? } \\
\hline $\begin{array}{l}\text { (0) No } \\
\text { (1) Yes, antibiotics of narrow spectrum, anti-inflammatory, analgesic } \\
\text { (2) Yes, anti-inflammatory, analgesic } \\
\text { *(3)Yes, broad spectrum antibiotics, anti-inflammatory and analgesic }\end{array}$ & $\begin{array}{c}11[6.4(3.4-10.9)] \\
36[21.1(15.3-27.4)] \\
29[17.0(12.0-23.3)] \\
95[55.6(48.2-62.9)]\end{array}$ \\
\hline $\begin{array}{l}\text { A patient who suffered an accident the day before arrives at the dental office. After radiographic examination it is observed that tooth no. } \\
21 \text { showed root fracture. } \\
\text { 3. The immediate treatment is: } \\
\text { (0) extraction of the tooth } \\
\text { (1) endodontic treatment } \\
\text { *(2) thermal test, rigid splint } \\
\text { (3) thermal test, semi-rigid splint }\end{array}$ & $\begin{array}{l}27[18.4(12.9-24.5)] \\
27[18.4(12.9-24.5)] \\
57[38.8(32.0-46.4)] \\
36[24.5(18.6-31.4)]\end{array}$ \\
\hline \multicolumn{2}{|l|}{ A patient came to the dental office with an avulsed tooth, kept dry for $7 \mathrm{~h}$. } \\
\hline \multicolumn{2}{|l|}{ 4. The immediate treatment is: } \\
\hline $\begin{array}{l}\text { (0) cleaning the root and the alveolar socket with saline solution, tooth replant, splint and antibiotics therapy. } \\
\text { *(1) place the tooth in a fluoride solution ( } 2.4 \% \text { sodium fluoride), cleaning of the alveolar socket with saline solution, replant, endodontic } \\
\text { treatment, splint and antibiotic therapy. } \\
\text { *(2) place the tooth in a fluoride solution ( } 2.4 \% \text { sodium fluoride), cleaning of the alveolar socket with saline solution, endodontic } \\
\text { treatment, replant, splint and antibiotic therapy. } \\
\text { (3) replacement of the missing tooth by prosthesis. }\end{array}$ & $\begin{array}{l}36[21.7(16.2-28.5)] \\
30[18.1(12.9-24.5)] \\
66[39.8(32.5-47.0)]\end{array}$ \\
\hline \multicolumn{2}{|l|}{$\begin{array}{l}\text { A } 7 \text { year-old boy who was hit in the face with a football, came to the dental office showing a fracture involving enamel and dentin with } \\
\text { pulp exposure. After radiographic examination it was verified that the stage of root formation was incomplete (open apex). }\end{array}$} \\
\hline $\begin{array}{l}\text { 5. The immediate treatment is: } \\
\text { (0) pulpectomy } \\
\text { *(1) pulpotomy } \\
\text { (2) endodontic treatment in one session }\end{array}$ & $\begin{array}{c}20[12.1(8.0-17.9)] \\
141[85.5(79.7-90.3)] \\
4[2.4(0.1-5.4)]\end{array}$ \\
\hline
\end{tabular}


Table 3 - Absolute and relative frequencies of the number of correct answers to the questions asked to dentists on dental trauma. Pelotas, Brazil $(\mathrm{n}=187)$.

\begin{tabular}{lcc}
\hline Number of correct answers & $\begin{array}{c}\text { Absolute frequency }(\mathrm{n}) \\
\text { Relative frequency } \\
{[\%(\mathrm{Cl}, 95 \%)]}\end{array}$ & $7.0(3.8-11.6)$ \\
\hline 0 & 13 & $13.9(9.3-19.7)$ \\
2 & 26 & $24.6(18.6-31.4)$ \\
3 & 46 & $28.9(22.5-35.9)$ \\
4 & 54 & $18.2(12.9-24.5)$ \\
5 & 34 & $7.5(4.2-12.2)$ \\
\hline
\end{tabular}

Table 4 - Absolute and relative frequencies of the number of correct answers to the questions asked to dentists on dental trauma. Pelotas, Brazil $(\mathrm{n}=187)$.

\begin{tabular}{|c|c|c|c|}
\hline \multirow[t]{2}{*}{ Variables/Categories } & \multicolumn{2}{|c|}{ Number of correct answers (\%) } & \multirow[t]{2}{*}{ p Value } \\
\hline & 0 to 2 & 3 to 5 & \\
\hline Total & $85(45.5)$ & $102(54.5)$ & \\
\hline Gender & & & $0.669^{*}$ \\
\hline Male & $39(43.8)$ & $50(56.2)$ & \\
\hline Female & $46(46.9)$ & $52(53.1)$ & \\
\hline Post-graduation & & & $0,556^{*}$ \\
\hline Without post-graduation & $32(48.5)$ & $34(51.5)$ & \\
\hline With post-graduation & $51(44.0)$ & $65(56.0)$ & \\
\hline Workplace & & & $0,550^{*}$ \\
\hline Private & $59(48.8)$ & $62(51.2)$ & \\
\hline Teaching & $16(41.0)$ & $23(59.0)$ & \\
\hline Public & $9(39.1)$ & $14(60.9)$ & \\
\hline Years since graduation & & & $0.004^{* *}$ \\
\hline Up to 10 & $30(35.7)$ & $54(64.3)$ & \\
\hline 11 to 20 & $20(46.5)$ & $23(53.5)$ & \\
\hline 21 to 30 & $14(50.0)$ & $14(50.0)$ & \\
\hline More than 30 & $20(66.7)$ & $10(33.3)$ & \\
\hline
\end{tabular}

* Chi Square Test $\left(\chi^{2}\right)$

** $\chi^{2}$ Test for linear trend

\section{Discussion}

The present study showed a low level of knowledge of dentists regarding management of dental injuries related to dento-alveolar trauma. Dentists were considered with a low level knowledge when these professionals scored 0 to 2 correct answers, which included $45.5 \%$ of the dentists interviewed. This low level of knowledge increased in a linear way with the increase in the time since graduation. Our findings are similar to the studies reported by $\mathrm{Hu}$ et al. ${ }^{9}$, Krasti et al. ${ }^{12}$, and De França et al. ${ }^{14}$ who also showed that recently graduated dentists presented a better knowledge of the techniques for treatment of dental trauma. On the other hand, Granville-Garcia et al. ${ }^{17}$ found a different result. In their study dentists presented a good knowledge for treatment of dento-alveolar trauma regardless the length of professional experience.

If we observe the descriptive analysis of variables related to dentists (Table 1), we could see that there is no predominance of gender among them, demonstrating an equality, which was not seen decades ago when the predominance of males in the profession reached $90 \%{ }^{18}$. Another variable that calls attention do to its great disproportion is skin color, where $96.8 \%$ of the dentists interviewed were white. The competition for admission in courses of high social prestige, e.g. dentistry, usually after expensive preparatory training, makes these courses real monopolies of higher social classes ${ }^{19}$. Thus, it is expected that black population, still economically disadvantaged in our country ${ }^{20}$, would be underrepresented in the profession.

Although the majority of dentists have some kind of specialization, in our study this variable did not contribute to the improvement of the knowledge in the management of dentoalveolar trauma. In the studies by $\mathrm{Hu}$ et al. ${ }^{9}$ and De França et al. ${ }^{14}$, dentists who worked in post-graduate courses or who had experience in dento-alveolar trauma presented a higher knowledge score than other professionals. Hu et al. ${ }^{9}$ also reported a poor correlation between time since graduation and knowledge score. In our study it was evident a clear correlation between years since graduation and decrease of knowledge $(p=0.004)$ which confirms the results obtained in a study by De França et al. ${ }^{14}$

The place where the dentist worked did not interfere in the knowledge; however a similar study in China compared the knowledge on dento-alveolar trauma among Chinese dentists from rural and urban areas, and observed a better knowledge in the dentists from the urban area. However, they concluded that in both cases it was found a low level of knowledge on management of dento-alveolar trauma ${ }^{21}$.

Yet, a study by Zadik et al. ${ }^{11}$ evaluated the data diffusion of IADT guidelines one year after publication in 2007, and showed that there was an increase in dentists knowledge, concluding that knowledge has to be reinforced.

In the first question (Table 2), more than half of the dentists interviewed chose semi-rigid splint, and this kind of splinting allows small physiological movements, which is desirable for periodontal healing and appears to reduce the risk of ankylosis and external root resorption when used for short periods ${ }^{22}$. In question 3, almost one quarter of the respondents $(24.5 \%)$, chose semi-rigid splint. This treatment is contrary to the one proposed by Sanabe et al. ${ }^{23}$ and by IADT guidelines 6 that recommend rigid splint, which would have better outcome in the treatment. In this case, in order to have the healing of the dentinal-cement complex, it is required the immobilization of the tooth.

In question 4 (Table 2) we considered two correct answers, based on a recent work by $\mathrm{Kumar}^{24}$, who reported that there is no difference in performing extra-oral or intra-oral endondontics. This is a discussion not yet well defined, as Pohl et al. ${ }^{25}$ argues that endodontic should be performed immediately after avulsion preferably extra-oral. In opposite, other studies argue that endodontic should be performed seven to ten days after the tooth replantation ${ }^{26-28}$, while other researchers suggest that the treatment should be performed for a period of two to three weeks ${ }^{29}$. Although there is disagreement regarding the time in which the endodontic treatment should be performed, all the researchers agree that ankylosis and root resorption substitution is present in all cases but it is the desirable outcome.

The last question was the one that the respondents obtained the highest relative frequency of correct answers $(85.5 \%)$ following IADT guidelines, that is, teeth with open apexes should be kept with their pulp vitality to ensure the root development and apex closure. The lack of standardized techniques for management 
of dental trauma, despite IADT guidelines has possibly been a hindrance to the acquisition of full knowledge. Our findings demonstrate the need to implement new strategies in order to improve dentist's knowledge regarding the management of injuries of dento-alveolar trauma.

The traditional dental curriculum presents limited opportunities for students to evaluate and treat patients with dental trauma. As a result of this lack of exposure, most graduating dentists are undertrained and ill-prepared to manage dental trauma ${ }^{30}$.

There is a need for courses in dental traumatology in the society to increase the knowledge level among the professionals. To improve the quality of education in dental trauma, continuing education through courses and seminars to dentists and the general public are important tools for improving this knowledge. Guidelines also contribute to a higher standard of care. Additionally, changings in the curriculum of dental institutions are necessary, aiming to improve the willingness of dentists to treat patients with traumatic dental injuries, the sustained knowledge of management of dental trauma, as well as the community involvement stimulated by the universities to support prevention ${ }^{31}$. Moreover, courses of the emergency management of traumatic injuries is an important topic to be covered ${ }^{30}$.

It is important to highlight that the use of questionnaires is a useful tool for data collection, allowing obtaining of data of good quantity in large geographic areas and in a short period of time. The enclosed and auto-applicable questionnaire had as an advantage to allow the dentists to answer the questions without interruption to their daily activities in the dental office. The disadvantage of this kind of auto-applicable questionnaire is that the dentist may not answer all the questions or may search for information when faced with questions that the answer is unknown.

In this study, the response rate was $68 \%$, with losses and refusals reduced by visiting the dental clinics at least twice to retrieve the questionnaires. This response rate is acceptable, since response rates of about $50 \%$ have been reported in similar surveys ${ }^{12,32-34}$. If the dentists were interviewed personally, instead of the auto-applicable version of the questionnaire, the presence of missing data in the questionnaire could be reduced, but a higher number of refusals could be expected, because the normal routine of the dental office would be disturbed or by the fear of not knowing the correct answer.

Within the limitations of the present study, we can conclude that:

1) The knowledge of the dentists regarding the management of dental injuries related to dento-alveolar trauma is less since the passing years after graduation pass because it seems there are no familiarity with current treatment guidelines;

2) Other independent variables such as gender, workplace and post-graduation were not associated to the number of correct answers;

3) Moreover, the findings of this study points out a lack of experience from professionals to perform some attendance without the appropriate knowledge to perform this. Changings int the dental curricula and continuing education courses should be offered to the dentists by educational institutions, in order to keep these professionals updated regarding management of dentoalveolar trauma injuries.

\section{References}

1. Lam R. Epidemiology and outcomes of traumatic dental injuries: a review of the literature. Aust Dent J. 2016 Mar;61 Suppl 1:4-20. doi: 10.1111/ adj.12395.

2. Damé-Teixeira N, Alves LS, Susin C, Maltz M. Traumatic dental injury among 12-year-old South Brazilian schoolchildren: prevalence, severity, and risk indicators. Dent Traumatol. 2013 Feb;29(1):52-8. doi: 10.1111/j.1600-9657.2012.01124.x.

3. Freire-Maia FB, Auad SM, de Abreu MHNG, Sardenberg F, Martins MT, Paiva SM, et al. Oral Health-Related Quality of Life and Traumatic Dental Injuries in Young Permanent Incisors in Brazilian Schoolchildren: A Multilevel Approach. PloS one 2015 Aug 19;10(8):e0135369. doi: 10.1371/journal.pone.0135369.

4. Soares FC, Cardoso M, Bolan M. Altered Esthetics in Primary Central Incisors: The Child's Perception. Pediatr Dent. 2015 SepOct;37(5):29-34.

5. Frujeri MDLV, Frujeri JÂJ, Bezerra ACB, Cortes MIDSG. Prevalence, Etiology and Treatment Needs of Traumatic Dental Injuries in Schoolchildren aged 12 years at Brasília, Brazil. Braz Res Pediat Dent Integr Clinic. 2015;15(1):65-73. Doi: 10.4034/PBOCI.2015.151.08.

6. International Association of Dental Traumatology - IADT. The Dental Trauma Guide. [Cited 2016 Sep 30]. Available from: http://www.iadtdentaltrauma.org .

7. Andersson L. The importance of guidelines. Dent Traumatol. 2007 Feb;23(1):65

8. Andreasen JO, Andreasen FM, Skeie A, Hjørting-Hansen E, Schwartz O. Effect of treatment delay upon pulp and periodontal healing of traumatic dental injuries - a review article. Dent Traumatol. 2002 Jun;18(3):116-28.

9. $\mathrm{Hu} \mathrm{LW}$, Prisco CRD, Bombana AC. Knowledge of Brazilian general dentists and endodontists about the emergency management of dentoalveolar trauma. Dent Traumatol. 2006 Jun;22(3):113-7.

10. Zaitoun H, North S, Lee S, Albadri S, McDonnell ST, Rodd HD. Initial management of paediatric dento-alveolar trauma in the permanent dentition: a multi-centre evaluation. Br Dent J. 2010 Mar 27;208(6):E11; discussion 254-5. doi: 10.1038/sj.bdj.2010.254.

11. Zadik Y, Marom Y, Levin L. Dental practitioners knowledge and implementation of the 2007 International Association of Dental Traumatology guidelines for management of dental trauma. Dent Traumatol. 2009 Oct;25(5):490-3. doi: 10.1111/j.16009657.2009.00805.x.

12. Krastl G, Filippi A, Weiger R. German general dentists' knowledge of dental trauma. Dent traumatol. 2009 Feb;25(1):88-91. doi: 10.1111/j.1600-9657.2008.00706.x.

13. Kostopoulou MN, Duggal MS. A study into dentists' knowledge of the treatment of traumatic injuries to young permanent incisors. Int $\mathrm{J}$ Paediatr Dent. 2005 Jan;15(1):10-9.

14. De França RI, Traebert J, Lacerda JT. Brazilian dentists' knowledge regarding immediate treatment of traumatic dental injuries. Dent Traumatol. 2007 Oct;23(5):287-90.

15. Santos MESM, Guerra Neto MG, Plameira PTDSS, Soares DM, Souza CMDA. [Level of knowledge of Nursing, Physical Education and Dentistry professionals on dentoalveolar trauma and avulsion]. Rev Cir Traumatol Buco-Maxilo-Fac. 2010 Jan-Mar;10(1):95-102. Portuguese.

16. Menezes MC, Carvalho RG, Accorsi-Mendonça T, De-Deus G, Moreira EJ, Silva EJ. Knowledge of Dentists on the Management of Tooth Avulsion Injuries in Rio de Janeiro, Brazil. Oral Health Prev Dent. 2015;13(5):457-60. doi: 10.3290/j.ohpd.a33923.

17. Granville-Garcia AF, Balduíno Junior JB, Ferreira JMS, Menezes VA, Fotes LBC, Cavalcanti AL. [Knowledge of the dentist about tooth avulsion at the Program Family Health in Campina Grande, PB, Brazil]. Odonto (Sao Bernardo Campo). 2009 Jan-Jun;17(33):35-41. Portuguese. 
18. Ward P. The changing shape of the dental profession. Br Dent J. 2008 Jan 12;204(1):1. doi: 10.1038/bdj.2007.1207.

19. Almeida-Filho N. Higher education and health care in Brazil. Lancet. 2011 Jun 4;377(9781):1898-900. doi: 10.1016/S0140-6736(11)60326-7.

20. Boakari FM. Black university students' perceptions of the future in Brazil's multi-racial society. World Stud Educ. 2005;6(2):53-83. doi: 10.7459/ wse/06.2.04.

21. Zhao Y, Gong Y. Knowledge of emergency management of avulsed teeth: a survey of dentists in Beijing, China. Dent Traumatol. 2010 Jun;26(3):281-4. doi: 10.1111/j.1600-9657.2010.00877.x.

22. Von Arx T, Filippi A, Buser D. Splinting of traumatized teeth with a new devise: TTS (Titanium Trauma Splint). Dent Traumatol. 2001 Aug;17(4):180-4.

23. Sanabe ME, Bezerra L, Cavalcante B, Coldebella CR, Abreu-eLima FCB. [Dental traumatism urgencies: classification, signs and procedures]. Rev Paul Pediatr. 2009 Dec;27(4):47-51. doi: 10.1590/ S0103-05822009000400015.

24. Kumar SKS. Extraoral endodontic treatment is not detrimental for avulsed permanent teeth replanted after more than 60 minutes' dry time. J Am Dent Assoc. 2010 Dec;141(12):1467-9.

25. Pohl Y, Fillipi A, Kirschner H. Results after replantation of avulsed permanent teeth. I. Endodontic considerations. Dent Traumatol. 2005 Apr;21(2):80-92.

26. Trope M. Clinical management of the avulsed tooth: present strategies and future directions. Dent Traumatol. 2002 Feb;18(1):1-11.

27. Flores MT, Andersson L, Andreasen JO, Bakland LK, Malmgren
B, Barnett F, et al. Guidelines for the management of traumatic dental injuries. II. Avulsion of permanent teeth. Dent Traumatol. 2007Jun;23(3):130-6.

28. Heithersay GS. Life cycles of traumatized teeth: longiterm observations from a cohort of dental trauma victims. Aust Dent J. 2016 Mar;61 Suppl 1:120-7. doi: 10.1111/adj.12403.

29. Vasconcelos BCE, Filho JRL, Fernandes BC, Aguiar ERB. [Dental Reimplantation]. Rev Cir Traumat Buco-Maxilo-Facial. 2001 JulDec;1(2):45-51.

30. Townsend J, King B, Ballard R, Armbruster P, Sabey K. Interdisciplinary approach to education: preparing general dentists to manage dental trauma. Dent Traumatol. 2017 Apr;33(2):143-148. doi: 10.1111/ edt.12309.

31. AbuIDawoud M, AlıEnezi B, Andersson L. Knowledge of emergency management of avulsed teeth among young physicians and dentists. Dent Traumatol. 2007 Dec;23(6):348-55.

32. Owen-Smith V, Burgess-Allen J, Lavelle K, Wilding E. Can lifestyle surveys survive a low response rate? J Public Health. 2008 Dec;122(12):1382-3. doi: 10.1016/j.puhe.2008.05.008.

33. Yeng T, Parashos P. An investigation into dentists' management methods of dental trauma to maxillary permanent incisors in Victoria, Australia. Dent Traumatol. 2008 Aug;24(4):443-8. doi: 10.1111/j.16009657.2008.00609.x.

34. Skaare AB, Pawlowski AA, Maseng Aas AL, Espelid I. Dentists' self estimation of their competence to treat avulsion and root fracture injuries. Dent Traumatol. 2015 Oct;31(5):368-73. doi: 10.1111/edt.12186. 